\title{
Impact of the configuration of stretching and ocean-atmosphere coupling on tropical cyclone activity in the variable-resolution GCM ARPEGE
}

\author{
Anne Sophie Daloz $\cdot$ Fabrice Chauvin • \\ Frank Roux
}

\begin{abstract}
This study starts by investigating the impact of the configuration of the variable-resolution atmospheric grid on tropical cyclone (TC) activity. The French atmospheric general circulation model ARPEGE, the grid of which is rotated and stretched over the North Atlantic basin, was used with prescribed sea surface temperatures. The study clearly shows that changing the position of the stretching pole strongly modifies the representation of TC activity over the North Atlantic basin. A pole in the centre of the North Atlantic basin provides the best representation of the TC activity for this region. In a second part, the variable-resolution climate model ARPEGE is coupled with the European oceanic global climate model NEMO in order to study the impact of ocean-atmosphere coupling on TC activity over the North Atlantic basin. Two preindustrial runs, a coupled simulation and a simulation forced by the sea surface temperatures from the coupled one, are compared. The results show that the coupled simulation is more active in the Caribbean Sea and the Gulf of Mexico while the forced simulation is more active over eastern Florida and the eastern Atlantic. The difference in the distribution of TC activity is certainly linked with the location of TC genesis. In the forced simulation, tropical cyclogenesis is closer to the west African coast than in the coupled simulation. Moreover, the difference in TC activity over the eastern Atlantic seems to be related to two
\end{abstract}

\footnotetext{
A. S. Daloz $(\bowtie) \cdot$ F. Chauvin

Groupe de Modélisation Grande Echelle et Climat, CNRM-GAME, 42 avenue G. Coriolis,

31057 Toulouse Cedex 1, France

e-mail: adaloz@wisc.edu

F. Roux

Laboratoire d'Aérologie, Centre National de la Recherche

Scientifique, Université de Toulouse, Toulouse, France
}

different mechanisms: the difference in African easterly wave activity over the west of Africa and the cooling produced, in the coupled simulation, by African easterly waves over the eastern Atlantic. Finally, the last part studies the impact of changing the frequency of oceanatmosphere coupling on Atlantic TC activity. Increasing the frequency of coupling decreases the density of TC activity over the North Atlantic basin. However, it does not modify the spatial distribution of the TC activity. TC rainfalls are decreased by $8 \%$ in the high frequency coupled run.

Keywords Tropical cyclone (TC) - African easterly wave (AEW) · Ocean-atmosphere coupling · Stretched · General circulation model (GCM) - Frequency of coupling

\section{Introduction}

One of the main goals of climate studies is to produce improved, physically based predictions of the effects of natural and anthropogenic perturbations on global and regional climates. Due to computational costs, climate models usually have a too coarse spatial resolution to explicitly represent tropical cyclone (TC) activity. One way to perform high resolution simulation over a limited area is to stretch the grid of the model over the region of interest. This method has been used and validated in operational forecasting and climate modelling studies (Fox-Rabinovitz et al. 2006; Chauvin et al. 2006; Caron et al. 2010). This technique has been applied to the French atmospheric general circulation model (AGCM), ARPEGE (Courtier and Geleyn 1988). In ARPEGE, the grid is rotated and stretched, providing a variable resolution with more grid points over the region of interest. Here, it is the 
North Atlantic basin. Over this region, the horizontal resolution varies between $50 \mathrm{~km}$ at the pole of stretching and around $100 \mathrm{~km}$ at the limits of the domain. The high resolution domain is placed in such a way as to obtain a more realistic representation of the Atlantic TC activity and the west African climate.

One of the specificities of TC activity over the North Atlantic basin is its strong dependence on tropical disturbances developing over west Africa (Landsea and Gray 1992). The link between these disturbances, called African easterly waves (AEWs), and Atlantic TCs was suggested by Carlson (1969) and has been the subject of many scientific investigations (Hopsch et al. 2007; Arnault and Roux 2011 among others). AEWs are well known features of the African climate during the boreal summer. These disturbances propagating in the mid- and low troposphere have been studied for many years, particularly during GATE (Global Atmospheric Research Programme's Atlantic Tropical Experiment) (Reed et al. 1977). Failure to simulate adequate AEW activity can have a negative impact on the ability of GCMs to represent Atlantic TC activity (Daloz et al. 2012). Here, we investigate the impact of modifying the position of the high-resolution domain on AEW and Atlantic TC activities.

In a second part, we use a high-resolution coupled atmosphere-ocean general circulation model (AOGCM) that includes comprehensive representations of the atmosphere and the upper ocean. This type of model offers unique possibilities for exploring the complex interactions between oceanic and atmospheric perturbations. In the case of TCs, the oceanic influence on their genesis and maintenance has long been recognized. The ocean is the energy source that allows TCs to develop and maintain deep convection (Malkus and Riehl 1960). Likewise, Murakami and Wang (2010) pointed out the importance of the spatial structure of future sea surface temperature (SST) warming. They showed that the TC changes were more sensitive to future changes in the spatial distribution of SST than to the trend in its global mean value. The importance of the SST is supported by theoretical studies showing a direct relationship between the SST and the intensity of storms (e.g. Emanuel 1988; Holland 1997). Coupling with the ocean can have a strong influence on storm intensity, primarily through the mixing and upwelling of cooler subsurface water to the surface in the vicinity of the storm (Bender et al. 1993; Bender and Ginis 2000; Emanuel 2003). The storm-induced cooling can lead to a SST decrease of $1^{\circ}$ to $6{ }^{\circ} \mathrm{C}$ (Price 1981). The characteristics of the cold wake depend on various factors, such as the size or the translation speed of the storm (Bender and Ginis 2000; Samson et al. 2009).

To investigate the impact of the ocean-atmosphere coupling on North Atlantic TC activity, the high-resolution
AGCM ARPEGE was run in two different configurations. One was fully coupled with an OGCM and the other was forced by SST taken from the coupled simulation. Because the ocean and the atmosphere interact in the AOGCM but not in the AGCM, one would expect to observe some differences in mean simulated TC activity between the coupled and forced simulations.

Due to the strong dependency between the SST and TCs, TC activity could be expected to be very sensitive to the coupling frequency. Although the literature does not report studies on the impact of the coupling frequency on TC activity (to our knowledge), several studies present its impact on other mechanisms. Bernie et al. (2005) and Renaudie (2009) showed the need for a high coupling frequency $(1 / 3 \mathrm{~h})$ in order to improve the simulation of the diurnal cycle of SST. Lebeaupin-Brossier et al. (2009) showed the importance of high coupling frequency for a good representation of the extreme precipitating systems in the Mediterranean Sea. Klingaman et al. (2011) pointed out the improvement in the simulation of intra-seasonal variations of the SST and the Indian monsoon when the vertical resolution of sub-surface ocean and the coupling frequency were increased.

The present study aims to explore how the simulated North Atlantic TC activity responds to first, a change in the configuration of the stretched grid and then to the introduction of ocean-atmosphere coupling. The influence of the frequency of coupling on TC activity will also be investigated. In the next section, the two configurations of the model are presented, together with the tracking methodology. The sensitivity of North Atlantic TC activity to the position of the high-resolution domain is discussed in Sect. 3. In section 4, the impact of ocean-atmosphere coupling on Atlantic TC activity is investigated. Particular attention is paid to the sensitivity of TC activity to the coupling frequency in Section 5. A summary and conclusions are given in Sect. 6.

\section{Data and methodology}

\subsection{Description of the stretched-rotated and coupled configuration of ARPEGE}

In the context of the CMIP-5 (Coupled Model Intercomparison Project Phase 5) exercise, CNRM-GAME and CERFACS developed a new version of the ocean-atmosphere coupled Climate Model: CNRM-CM5 (Voldoire et al. 2011). As shown in Fig. 1, CNRM-CM5 associates the ARPEGE AGCM with the SURFEX externalized surface scheme and the NEMO oceanic GCM (Madec 2008). NEMO is also coupled with the TRIP river routing model (Oki and Sud 1998). The longwave radiation scheme in the 


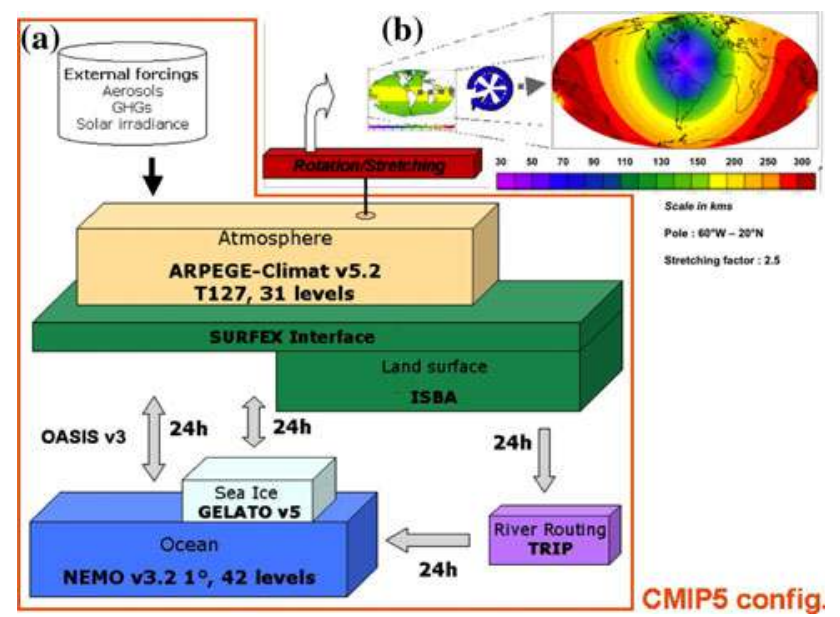

Fig. 1 a Components of the CNRM-CM5 coupled climate model (delimited by the red box), b grid stretched and rotated with a stretching factor of 2.5 (top right)

atmosphere is the ECMWF Rapid Radiation Transfer Model (Mlawer et al. 1997). Sea-ice interactions are represented by the GELATO sea ice scheme (Salas-Mélia 2002). For this study, NEMO was used with a $1^{\circ}$ horizontal resolution and 42 levels with a vertical resolution varying from $10 \mathrm{~m}$ at the surface to $300 \mathrm{~m}$ at $5,000-\mathrm{m}$ depth. ARPEGE and NEMO were coupled through the OASIS interface (Valcke 2006).

The ARPEGE climate model originates from the ARPEGE/IFS (Integrated Forecast System) numerical weather prediction model, developed jointly by Météo-France and ECMWF. Thirty-one vertical levels are defined with a progressive hybrid $\sigma$-pressure vertical coordinate. The physical package includes the deep convection scheme described in Bougeault (1985) and the statistical cloud scheme of Ricard and Royer (1993). Aerosol distribution is from outputs of the LMDZ-INCA chemical model (Szopa et al. 2012; Schultz 2007), forced with observed and prescribed surface emissions.

As mentioned earlier, CNRM-CM5 was used in a particular configuration for the study of TC over the North Atlantic. The horizontal grid of the atmospheric model was rotated and stretched (Courtier and Geleyn 1988) with a focus over the North Atlantic basin and its high-resolution pole at $20^{\circ} \mathrm{N}, 60^{\circ} \mathrm{W}$. The variable-resolution atmospheric grid is presented in Fig. 1. A stretching factor of 2.5 leads to a horizontal resolution of $60-100 \mathrm{~km}$ over the tropical Atlantic. Resolution decreases linearly with distance from the pole to reach approximately $310 \mathrm{~km}$ at the opposite pole $\left(20^{\circ} \mathrm{S}, 120^{\circ} \mathrm{E}\right)$. It has also been validated for the study of the TC activity in the North Atlantic basin by Chauvin et al. (2006) who showed that, with this technique and for sufficiently high spatial resolution, ARPEGE is able to represent realistic TC structures.
In order to study the impact of ocean-atmosphere coupling on simulated TC activity (Sect. 4), two rotatedstretched pre-industrial experiments were performed. Preindustrial runs were preferred to historical simulations in order to focus on the impact of ocean-atmosphere coupling and avoid the influence of the historical trend in the climate due to GHG concentrations. Thus, it was possible to focus on the influence of coupling alone on TC activity. The "pre-industrial coupled" simulation (COUPLE, cf. Table 1) included full ocean-atmosphere coupling, with greenhouse gas (GHG) concentrations fixed at their 1850 level and no natural forcing (volcanoes or solar) included. An atmospheric "pre-industrial forced" simulation (FORCE, cf. Table 1) was also performed, with similar atmospheric forcing but with prescribed SST values taken from COUPLE. The COUPLE simulation was run for 215 years, but only the last 107 years were taken into account to avoid the initial drift due to atmosphere-ocean adjustment. We verified that the biases of this simulation with respect to climatology were similar to those from CNRM-CM5 simulations with equivalent uniform resolution. In COUPLE, coupling between ARPEGE and NEMO was done daily.

For the forced run with the atmospheric model (FORCE), the following technique was used to prescribe the SSTs. It was considered that a daily forcing with SSTs from COUPLE would be meaningless since such high frequency SSTs would not be in equilibrium with the atmospheric fields produced by the AGCM. Moreover, on a daily timescale, variations of SST fields mostly result from atmospheric processes and do not represent forcing factors. Therefore, SSTs were averaged on a monthly basis and then daily interpolated using a quadratic function that preserved the monthly means. As a result, between the two simulations, SSTs differed only by their intra-monthly fluctuations, which were smoothed in the forced run. One consequence of this choice was that the oceanic cold wake produced by a TC was largely smoothed in FORCE.

In CNRM-CM5 the coupling frequency between the models of atmosphere and ocean is $1 / 24 \mathrm{~h}$. Given the strong dependency of TC activity on SSTs (Holland 1997; Emanuel 2005), it can be assumed that TCs are very sensitive to coupling frequency. In order to study the impact of the coupling frequency, two rotated-stretched coupled present-climate experiments, COUPLE24 and COUPLE3, were performed. They are presented in Table 1. COUPLE24 and COUPLE3 had the same configuration except that COUPLE2 4 had a coupling frequency of $1 / 24 \mathrm{~h}$ and COUPLE3 had $1 / 3 \mathrm{~h}$. These simulations included full ocean-atmosphere coupling, with greenhouse gas (GHG) concentrations varying from those of 1850-1994 and no natural forcing (volcanoes or solar) included. 
Table 1 Summary of the simulations performed with the variable-resolution model ARPEGE

\begin{tabular}{|c|c|c|c|c|c|}
\hline Simulations & Time period covered & Coupled or forced & Position of the pole & Coupling frequency & CONV \\
\hline ARPEGE & $1950-1999$ & $\begin{array}{l}\text { F with observed Hadley SST } \\
\text { (Rayner et al. 2003) }\end{array}$ & $20^{\circ} \mathrm{N}-60^{\circ} \mathrm{W}$ & $\mathrm{x}$ & $\mathrm{x}$ \\
\hline ARPEGE-EAST & Id. ARPEGE & Id. ARPEGE & $10^{\circ} \mathrm{N}-20^{\circ} \mathrm{W}$ & $\mathrm{x}$ & $\mathrm{x}$ \\
\hline ARPEGE-CONV & Id. ARPEGE & Id. ARPEGE & Id. ARPEGE & $\mathrm{x}$ & Activated \\
\hline COUPLE24 & $1850-1994$ & Coupled with NEMO & Id. ARPEGE & $1 / 24 \mathrm{~h}$ & $\mathrm{x}$ \\
\hline COUPLE3 & Id. COUPLE24 & Id. COUPLE24 & Id. ARPEGE & $1 / 3 \mathrm{~h}$ & $\mathrm{x}$ \\
\hline COUPLE & Preindustrial runs $=$ GHG of 1850 & Id. COUPLE24 & Id. ARPEGE & $1 / 24 \mathrm{~h}$ & $\mathrm{x}$ \\
\hline FORCE & Id. COUPLE & F with SST from COUPLE & Id. ARPEGE & $\mathrm{x}$ & $\mathrm{x}$ \\
\hline
\end{tabular}

\subsection{Tracking methodology}

In order to track simulated tropical storms, Chauvin et al. (2006) used the method developed at Météo-France by Ayrault and Joly (2000) to track mid-latitude lows and adapted it for TCs. To reconstruct TC tracks, the following criteria from Bengtsson et al. (1995) were considered:

1. Mean sea level pressure is a local minimum (therefore considered as the centre of the system);

2. $850 \mathrm{hPa}$ vorticity is larger than $5 \times 10^{-5} \mathrm{~s}^{-1}$;

3. $850 \mathrm{hPa}$ wind intensity is larger than $5 \mathrm{~m} \mathrm{~s}^{-1}$;

4. Mean $700-300 \mathrm{hPa}$ temperature anomaly is larger than $1 \mathrm{~K}$;

5. Temperature difference between 300 and $850 \mathrm{hPa}$ is larger than $2 \mathrm{~K}$;

6. Tangential wind difference between 850 and $300 \mathrm{hPa}$ is larger than $5 \mathrm{~m} \mathrm{~s}^{-1}$.

Anomalies were defined as the difference between the grid point considered and its environment. In order to separate the system from its environment, and given the quasi-symmetric structure of hurricanes, a reference disc radius was introduced, which was thought of as a characteristic dimension for the system. It was calculated, assuming that the size of the TC could be determined from the distance between the centre of the TC and the circle for which the mean radial pressure gradient was maximum. Thus the TC and its environment could be defined relatively to the reference disc radius. More details can be found in Chauvin et al. (2006). In this study, the TC and its environment radius were fixed at one and three times the reference disc radius. At a given time step, a grid point had to fulfil all the conditions to be selected for a TC track. The threshold values were chosen subjectively, in agreement with previously published values and to fit in with observed climatology of TC activity. This tracking method is similar to the one in Chauvin et al. (2006) with, however, differences for the criteria 4, 5 and 6. In Chauvin et al. (2006), the threshold criteria 5 and 6 were:
5. $300 \mathrm{hPa}$ temperature anomaly $>850 \mathrm{hPa}$ temperature anomaly,

6. $850 \mathrm{hPa}$ wind $>300 \mathrm{hPa}$ wind.

These criteria were too restrictive in terms of number of TCs and they had to be relaxed in order to increase the detection. Now, criteria 5 and 6 allow more accurate discrimination between mid-latitude and TCs. In simulations with SST prescribed from observations, criterion 4 was set to $3 \mathrm{~K}$, as in Chauvin et al. (2006). However, in coupled simulations, criterion 4 was set to $1 \mathrm{~K}$. This criterion was too restrictive for coupled simulations.

When tracking TC vortices (Bengtsson et al. 1982, 1995) in model simulations, the choice of the thresholds for the six criteria is somewhat arbitrary and may lead to biases. For example, a single cyclonic system may be split into several tracks if it loses the TC conditions then meets them again during its lifetime. The number of tracks in the simulation would therefore be overestimated. Camargo and Zebiak (2002) introduced a methodology to complete tracks by relaxing all the criteria, except vorticity, after the tracks had been constructed in a first guess. More details on relaxation can be found in Camargo and Zebiak (2002). Relaxed tracks were used here to identify the number of TCs in FORCE and COUPLE model results. Non-relaxed tracks usually contained discontinuous tracks, so counting the number of tracks in non-relaxed conditions would have implied counting the same TC several times. For statistics covering TC days, non-relaxed tracks were considered, so occurrences were assumed to fulfil the TC criteria.

\section{Sensitivity of TC activity to the position of the pole of stretching}

The technique for stretching and rotating the grid in ARPEGE allows a considerable increase in the spatial resolution over the North Atlantic basin for a limited cost. However, the selected configuration, with horizontal resolution being maximal (around $60 \mathrm{~km}$ ) at the stretching pole 
$\left(60^{\circ} \mathrm{W}-20^{\circ} \mathrm{N}\right)$ and then decreasing over the North Atlantic basin, reached around $100 \mathrm{~km}$ over the African coast. This configuration was used for the simulation called ARPEGE (cf. Table 1). The question whether the non-uniformity of the atmospheric grid could modify the representation of the TC activity can then be raised. Therefore, a simulation was run with the pole on the border of the west African coast $\left(10^{\circ} \mathrm{N}-20^{\circ} \mathrm{W}\right)$. It was called ARPEGE_EAST (cf. Table 1$)$. The maximum of spatial resolution was thus located in the area where AEWs occurred frequently.

Figure 2 presents TC track density per 20 years per $2^{\circ} \times 2^{\circ}$ grid cell for ARPEGE (a) and ARPEGE-EAST (b) over the North Atlantic basin for the time period 1950-1999. Figure 2a shows a maximum of TC activity over the western part of the basin, located over the Gulf of Mexico, the Caribbean Sea and east of Florida. A maximum is also visible in the eastern part of the basin, over the MDR, but its amplitude is weaker compared to the western one. For ARPEGE-EAST, Fig. 2b shows maxima of TC activity over the western and eastern parts of the basin with similar amplitude. ARPEGE-EAST presents a more homogeneous distribution of TC activity than ARPEGE over the Atlantic basin. This difference in spatial distribution is illustrated in Fig. 2c, which presents the difference between ARPEGE and ARPEGE-EAST in number of TC track. As already shown in raw density figures, ARPEGE shows a much higher (lower) density of TC occurrences than ARPEGE-EAST over the west (east) of the Atlantic basin. Therefore, moving the stretching pole has a non-negligible effect on the spatial distribution of the North Atlantic TC activity. The reasons for this difference will be explained later.

It is now interesting to determine which of ARPEGE or ARPEGE_EAST provides the most realistic TC distribution. Figure $2 \mathrm{~d}$ presents the TC track density per 20 years for the observations from IBTrACS (Knapp et al. 2010) over the time period 1950-1999. IBTrACS presents several maxima of TC activity. Classifying these maxima in order of decreasing amplitude shows that east Florida has the highest density (42 TC track occurrences per 20 years), followed by the Gulf of Mexico and the Caribbean Sea (32 TC track occurrences per 20 years) and finally the MDR (32 TC track occurrences per 20 years). If we now compare the simulations (Fig. 2a, b) with the observations (Fig. 2d), the maximum of TC activity over east Florida is well located in both simulations. In terms of amplitude, it is slightly underestimated by ARPEGE (32 TC track occurrences per 20 years) while it is seriously underestimated by (a) ARPEGE

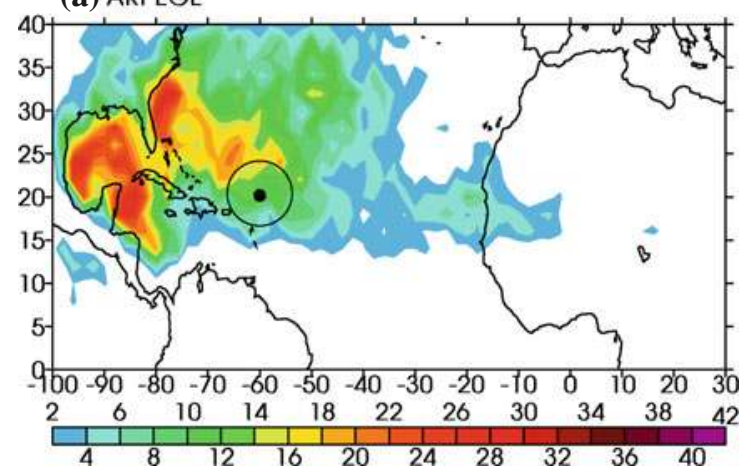

(c) ARPEGE - ARPEGE_EAST

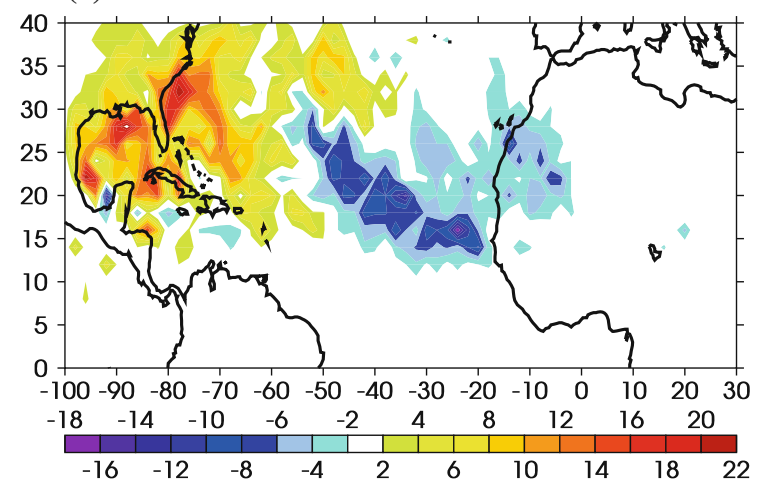

(b) ARPEGE_EAST

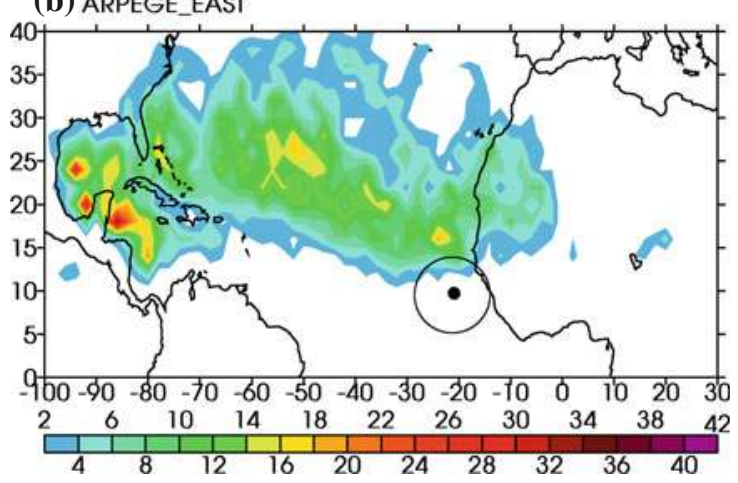

(d) IBTrACS

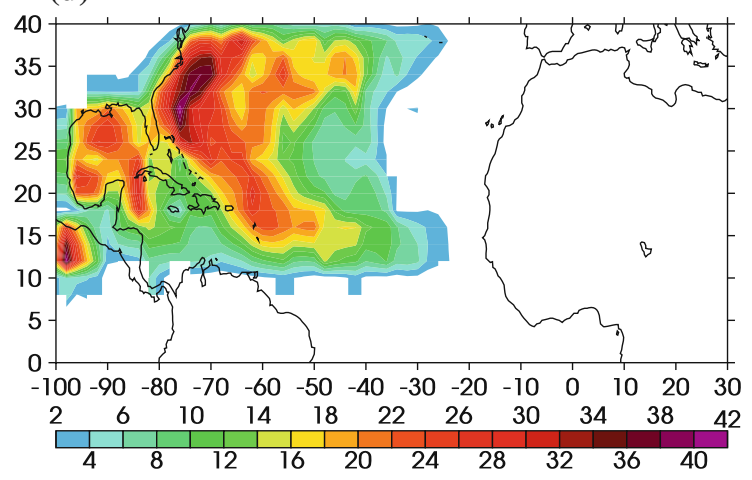

Fig. 2 TC track density per 20 years over a $2^{\circ}$ by $2^{\circ}$ grid over the North Atlantic basin for ARPEGE a ARPEGE-EAST, b the difference (ARPEGE-ARPEGE-EAST), $\mathbf{c}$ and IBTrACS, $\mathbf{d}$ from 1950 to 1999. The circle with the dot inside indicates the position of the grid pole 
ARPEGE-EAST (12 TC track occurrences per 20 years). Over the Gulf of Mexico and the Caribbean Sea, both simulations detect the maxima at the right positions but their amplitudes are very different. ARPEGE gives a good representation of the amplitude (32 TC track occurrences per 20 years) while ARPEGE-EAST clearly underestimates it (18 TC track occurrences per 20 years). The maximum observed over the western part of the MDR, North of the West Indies is largely underestimated in ARPEGE and quasi inexistent in ARPEGE-EAST. Finally, TC activity just offshore Africa is overestimated in both simulations with a quite larger bias in ARPEGE-EAST than in ARPEGE. Maybe the limits of comparison with observations are reached here, since TCs detected in models are not exactly the same objects as in observations. Eastern Atlantic is a region of cyclogenesis and IBTrACS takes into account the only systems that reach the tropical storm level. At the contrary, tracking in the models do not distinguish among the systems and thresholds for detection are lower than in reality $\left(15 \mathrm{~m} \mathrm{~s}^{-1}\right.$ here). This may explain why TC activity is overestimated in this region. From the comparison of ARPEGE and ARPEGE_EAST with the observations, we can see that the TC activity in ARPEGE_EAST is largely underestimated over the western part of the North Atlantic basin and overestimated over the eastern one. A more realistic representation of TC activity is produced by ARPEGE with a stretching pole in the centre of the North Atlantic basin. The distribution of TC activity, especially in the western part of the basin is closer to the observations in ARPEGE than ARPEGE_EAST.

Different factors can explain the differences in TC density between ARPEGE and ARPEGE_EAST. Over the western part of the basin, higher activity in ARPEGE compared to ARPEGE-EAST is likely due to the direct effect of the higher horizontal resolution. Over that region, the horizontal resolution of ARPEGE (around $60 \mathrm{~km}$ ) is much higher than that of ARPEGE-EAST (between 80 and $100 \mathrm{~km}$ ). On the other hand, on the eastern part of the basin, given the strong link between TC activity over the MDR and the AEW activity in the models (Daloz et al. 2012), we could expect higher TC activity over the MDR in ARPEGE_EAST to be directly related to the higher resolution on this region or to be an indirect effect of increased resolution over the region where AEWs occur frequently (or a combination of the two).

Figure 3 presents the 2-6 day filtered meridional wind variance at $850 \mathrm{hPa}$ over western Africa for the time period 1950-1999 for ARPEGE (a), ARPEGE-EAST (b), the difference between ARPEGE and ARPEGE-EAST (c) and the reanalysis ERA-40 (d) and NCEP-2 (e). In this temporal window, a maximum of variance is considered as a maximum of AEW activity. Both simulations present a maximum of AEW activity in the same area, around $15^{\circ} \mathrm{N}-10^{\circ} \mathrm{W}$ in the continent-ocean transition of west Africa. However, the amplitude of this maximum is higher in ARPEGE $\left(19 \mathrm{~m}^{2} \mathrm{~s}^{-2}\right.$, Fig. 3a) than in ARPEGE-EAST $\left(16 \mathrm{~m}^{2} \mathrm{~s}^{-2}\right.$, Fig. 3b). This difference is even more visible in Fig. 3c, with ARPEGE presenting an AEW activity $2.8 \mathrm{~m}^{2} \mathrm{~s}^{-2}$ higher than ARPEGE-EAST. It represents a difference of around $15 \%$ of the AEW activity. Thus the stronger TC activity cannot be explained by changes in AEW activity. At least, the effect of decreased AEW in ARPEGE-EAST is masked by another positive feedback on TC activity.

Nevertheless, since ARPEGE and ARPEGE-EAST show a noticeable difference in their AEW activity, it is of importance to understand what are the mechanisms which may explain it, given the known impact of these systems on cyclogenesis. Figure $3 d$ and e present the 2-6 day filtered meridional wind variance at $850 \mathrm{hPa}$ for the reanalysis ERA-40 $\left(1.12^{\circ} \times 1.12^{\circ}\right.$, Uppala et al. 2005) and NCEP-2 $\left(1.875^{\circ} \times 1.875^{\circ}\right.$, Kanamitsu et al. 2002) respectively. The reanalysis also give a maximum of AEW activity over the ocean-continent transition of west Africa with an amplitude of about $8 \mathrm{~m}^{2} \mathrm{~s}^{-2}$ for NCEP-2 (Fig. 3e) and $12 \mathrm{~m}^{2} \mathrm{~s}^{-2}$ for ERA-40 (Fig. 3d). Concerning the position of the maximum, the simulations are consistent with the reanalysis, they detect maxima of AEW activity over the ocean and the continent. In terms of amplitude, both simulations largely overestimate the activity, the bias being even higher for ARPEGE. Therefore, in terms of AEW activity, ARPEGEEAST is more realistic than ARPEGE. A part of the difference between the simulations and the reanalysis can certainly be attributed to the higher spatial resolution of the model. However, as Ruti and Dell Aquilla (2010) showed, for some models the spatial resolution is not the only reason for differences in the representation of AEW activity. Surface forcing is another source of variability for AEWs.

Figure 4 presents the difference in mean precipitation (a) and surface temperature (b) for July-August-September (JAS) between ARPEGE and ARPEGE-EAST over the North Atlantic basin. Over the area of AEW activity $\left(12^{\circ} \mathrm{N}\right.$; $30^{\circ} \mathrm{W}-30^{\circ} \mathrm{E}$ ), ARPEGE-EAST produces more precipitation than ARPEGE even though, over this region, ARPEGEEAST shows a weaker AEW activity than ARPEGE (cf. Fig. 3c). As resolution increases, convection processes start being resolved explicitly and tend to add to parametrized one to produce higher precipitation. This is illustrated in Fig. 4a, comparing mean seasonal precipitation difference between of ARPEGE-EAST and ARPEGE over the Atlantic and West Africa. Therefore, higher convection leads to better chances for TCs to develop. Figure $4 \mathrm{~b}$ presents the difference in surface temperature between the two simulations. It shows that the higher precipitation of ARPEGE-EAST (Fig. 4a) tends to cool continental west Africa. Although Hsieh and Cook (2005) argued that AEWs are linked with the strength of the Inter-Tropical Convergence Zone, increased 
(a) ARPEGE

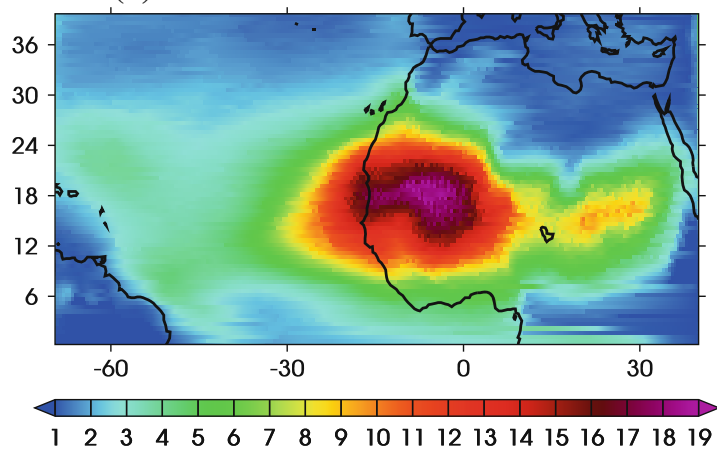

(c) ARPEGE - ARPEGE_EAST

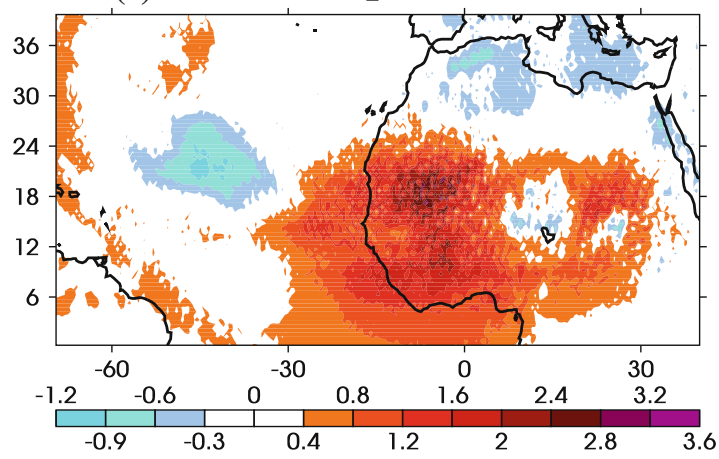

(d) era40

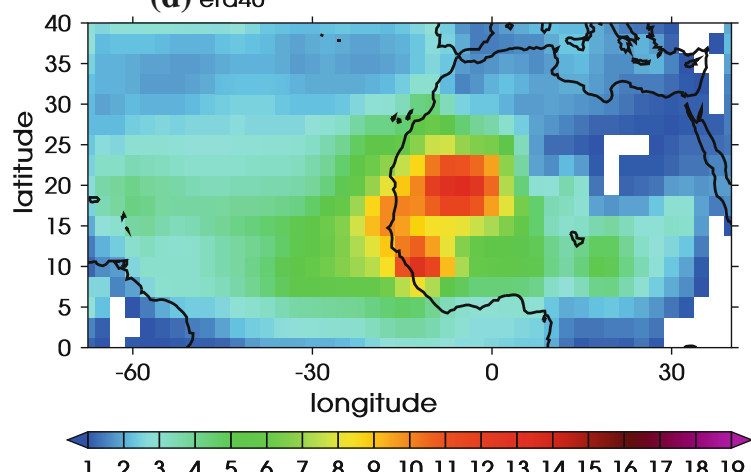

Fig. 3 2-6 day filtered meridional wind variance at $850 \mathrm{hPa}$ $\left(\mathrm{m}^{2} \mathrm{~s}^{-2}\right)$ over continental west Africa and the eastern North Atlantic basin for ARPEGE a ARPEGE-EAST, b the difference (c ARPEGE-

precipitation also induces changes in the North-South thermal gradient between Sahel and vegetation-covered Guinean coast. Ruti and Dell Aquilla (2010) found this gradient to be linked with integrated seasonal AEWs activity through its impact on baroclinic processes which are known to be a major cause in AEWs generation (Burpee 1972). Our hypothesis is that, in Fig. 4b, the higher precipitation from ARPEGE-EAST cools west Africa, decreasing the continent thermal gradient. This lower thermal gradient induces a less favourable environment for the formation and development of AEWs. This should lead to a decreased TC activity off Africa but the increased convection acts in the opposite way and leads to more TCs.

\section{(b) ARPEGE_EAST}

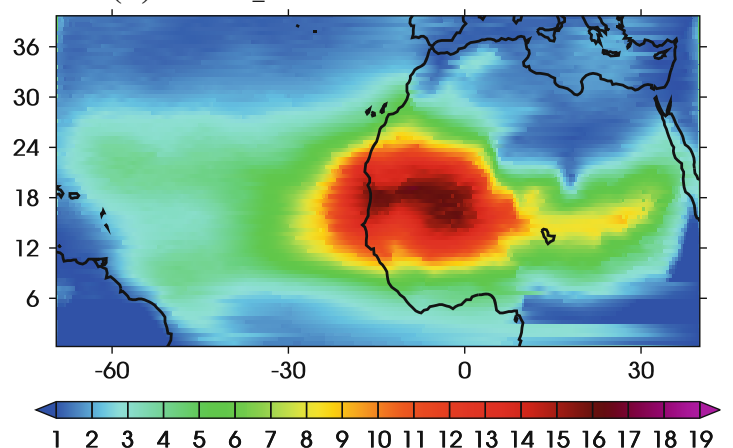

(e) ncep2

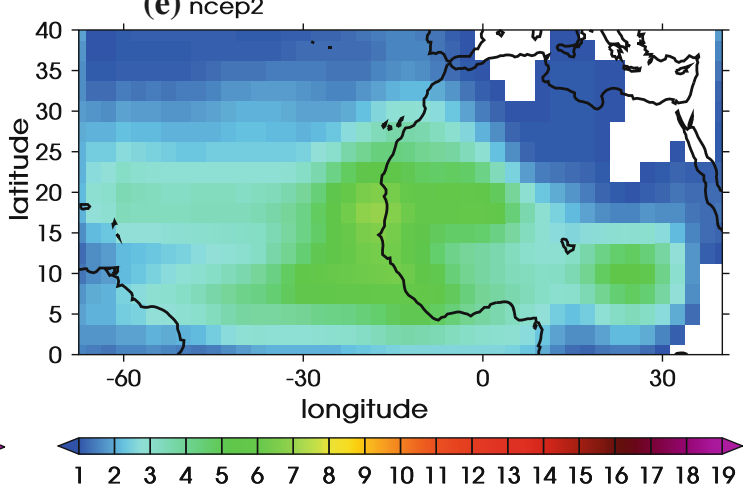

ARPEGE_EAST) for 1950-1999, and the reanalysis ERA-40 (d) and NCEP-2 e from 1980 to 2000

The difference in precipitation presented in Fig. 4a can be explained by the modification of a parameter in the convective scheme called CONV. In the stretched simulations, the resolution increases as the pole of stretching is approached. Where the resolution is higher, convection begins to be resolved explicitly, meaning that the parameterized convection must be reduced. For this purpose, CONV was introduced into the convective scheme in order to decrease the convergence of humidity when resolution increases. However, this parameter had already been identified as an inhibitive parameter for TC activity (Chauvin et al. 2006). Thus, for this set of experiments we chose to suppress the CONV effect to keep TC activity but 
(a) Precipitation

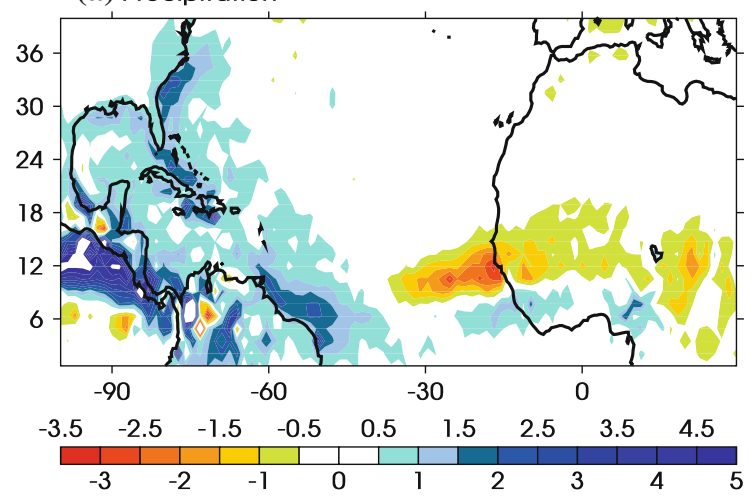

(b) Surface temperature

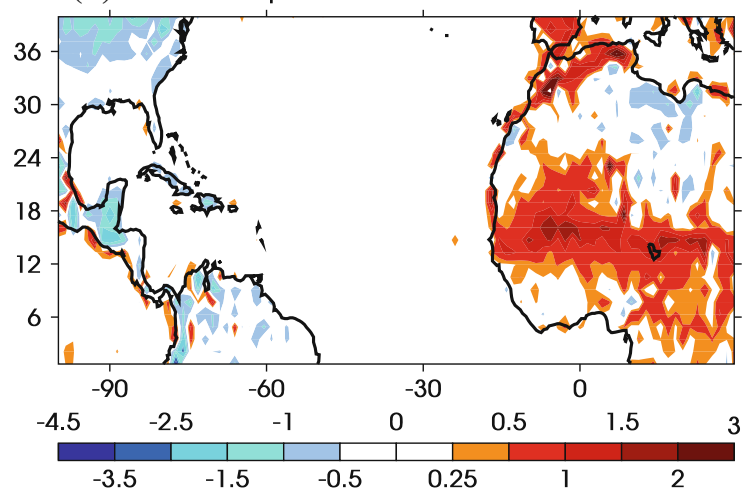

Fig. 4 Difference between ARPEGE and ARPEGE-EAST over continental west Africa and the eastern North Atlantic basin in precipitation $\left(\mathrm{mm} \mathrm{day}^{-1}\right)(\mathbf{a})$ and surface temperature $\left({ }^{\circ} \mathrm{C}\right)(\mathbf{b})$ from 1950 to 1999

are nevertheless conscious that a precipitation bias related to local resolution exists.

Finally, as shown in Fig. 2, track density over the Atlantic basin is better represented in the simulation where the grid pole is located in the vicinity of TC activity rather than in the pre-genesis region. The ARPEGE configuration was kept for the rest of the study.

\section{Sensitivity of TC activity to ocean-atmosphere coupling}

Figure 5 presents the TC track density per 20 years per $2^{\circ} \times 2^{\circ}$ grid cells, detected in COUPLE (a) and FORCE (b, cf. Table 1) over 107 years of simulation. To compare COUPLE and FORCE more precisely, different areas of important TC activity were defined as:

- NWATL (North Western ATLantic: 20-40 N, $\left.40-80^{\circ} \mathrm{W}\right)$ covers the subtropical latitudes experiencing TC activity;

- CWATL (Centre Western ATLantic: 20-30 N, $\left.80-95^{\circ} \mathrm{W}\right)$ covers the Gulf of Mexico;

- SWATL (South Western ATLantic: 5-20 N, 65-90 W) covers the Caribbean Sea;

- EATL (Eastern ATLantic: 5-20N, $15-65^{\circ} \mathrm{W}$ ) covers the Main Development Region (MDR, Goldenberg and Shapiro 1996);

- NATL is defined as the sum of the four sub-domains (NWATL, CWATL, SWATL and EATL).

Table 2 shows the mean number of TC track occurrences per 20 years and the relative contribution to the Atlantic TC activity in the four sub-domains, for COUPLE, FORCE and IBTrACS. The total number of TC track occurrences over the North Atlantic basin is nearly the same for the coupled (3336 TC track occurrences) and forced (3352 TC track occurrences) simulations. This number is very close to the mean number of IBTrACS (3368 TC track occurrences). Table 2 also reveals that EATL is the sub-domain contributing the most to TC activity over the North Atlantic basin for COUPLE (37\%) and FORCE (39\%). In the observations, NWATL is the main contributing sub-domain with $57 \%$ of the North Atlantic TC activity. The relative contribution of NWATL is clearly underestimated in the numerical results for FORCE (24\%) and even more so for COUPLE $(20 \%)$. SWATL is the most active sub-domain after EATL for COUPLE (30\%) and FORCE (26\%) while, for IBTrACS, it is EATL (19\%). For the simulations, CWATL contributes the least to the North Atlantic TC activity with percentages around $10 \%$. This region is well represented by both simulations, which present nearly the same percentage as the observations.

Figure 5c highlights the differences in TC track density per 20 years in $2^{\circ} \times 2^{\circ}$ grid cells between the coupled and forced simulations (FORCE minus COUPLE). COUPLE is clearly more active over CWATL and SWATL, whereas FORCE is more active over EATL and NWATL. In this figure, it appears that TCs in FORCE experience early recurvature and then move northward, showing a different pattern of TC activity between COUPLE and FORCE, which could be seen as an "east/west competition" between the eastern and western North Atlantic basin. This competition is clearly evident in Fig. 5d, showing diffrences in cyclogenesis between the two simulations. FORCE tends to allow cyclogenesis earlier than COUPLE, and so as for recurving of the tracks to the North. All these recurved tracks lack to reach the West Indies and Caribbean sea. Before analysing the differences between the coupled and forced simulations more deeply, it is important to look at the significance of the differences.

In order to address this problem, the difference of density of TC track occurrences was aggregated for each year over a $10^{\circ} \times 10^{\circ}$ grid cell (Fig. 6a). Aggregation makes 
(a) COUPLE

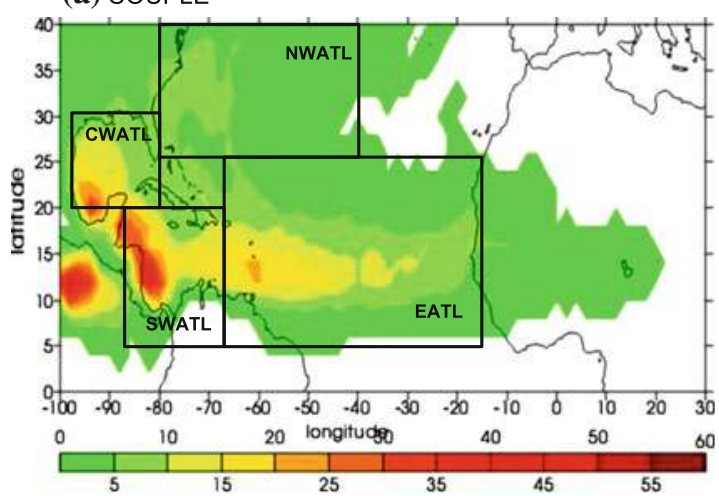

(c) FORCE - COUPLE

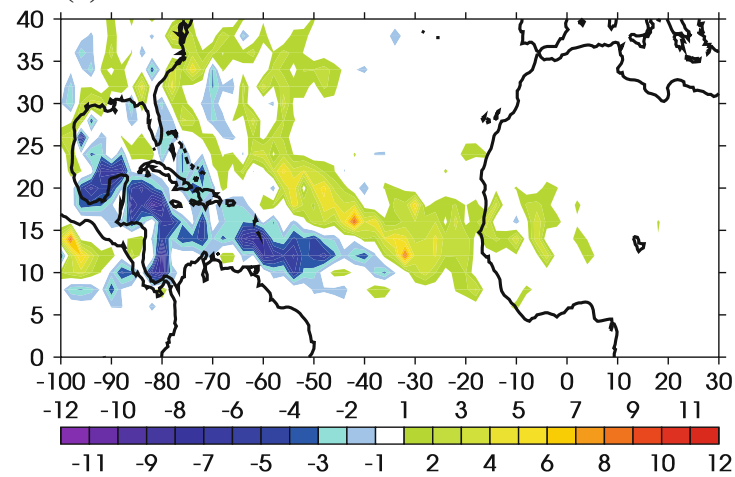

(b) FORCE

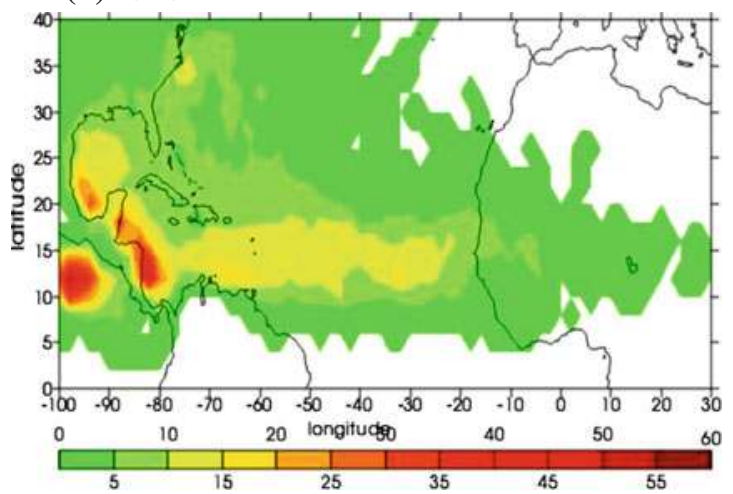

(d) FORCE - COUPLE

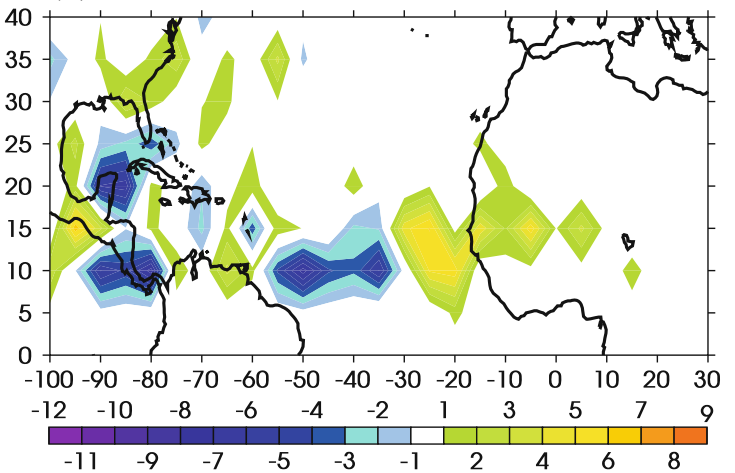

Fig. 5 Same as Fig. 2a-c but for FORCE and COUPLE over 107 years of simulation. The boxes indicate the sub-domains used in this study. Difference in TC genesis per 50 years between FORCE and COUPLE (d)

Table 2 Density of TC occurrences per twenty years, averaged over 107 years of simulations for FORCE (left column) and COUPLE (central column), and over 1950-2007 for IBTrACS (right column), for the North Atlantic basin (NATL) and the four sub-domains (NWATL, CWATL, SWATL, EATL) defined in the text

\begin{tabular}{lccc}
\hline Domains & COUPLE & FORCE & IBTrACS \\
\hline NWATL & $672(20)$ & $992(24)$ & $1936(57)$ \\
CWATL & $416(12)$ & $368(11)$ & $440(13)$ \\
SWATL & $1,008(30)$ & $872(26)$ & $368(11)$ \\
EATL & $1,240(37)$ & $1,304(39)$ & $624(19)$ \\
NATL & 3,336 & 3,352 & 3,368
\end{tabular}

Numbers in parentheses indicate the contribution (in \%) of each subdomain to the North Atlantic total

the density more continuous from 1 year to another and accounts for spatial coherency. The significance of the differences between FORCE and COUPLE in each $10^{\circ} \times 10^{\circ}$ grid cell was tested using a bootstrap method (Fig. 6b). For this test, we constructed a population of 214 elements bringing together the populations from FORCE and COUPLE, which contained 107 elements each. In the combined population, the same operation of drawing two samples of 107 values from the 214 possible values was performed 10,000 times. These operations gave us the distribution of the differences between FORCE and COUPLE. The null hypothesis of the significance test was that the differences between FORCE and COUPLE were not significantly different from zero. The real difference between COUPLE and FORCE may be compared to the distribution of differences under the null hypothesis and probability that it is outside may be calculated. The "east/ west competition" pattern already identified on Fig. $5 \mathrm{c}$ is even more visible in Fig. 6a. Figure $6 \mathrm{~b}$ presents the level of significance of the differences. The difference between FORCE and COUPLE is clearly significant (over 95\%) over the centre of the Atlantic, the MDR and some points on the eastern coast of Florida. Looking at a cyclogenesis index (Royer et al. 1998), we have seen that the differences between the coupled and forced simulations are weak meaning that changes in TC activity are not due to largescale environment changing conditions (not shown).

Table 2 indicates that one of the main contributions to the number of TCs simulated in COUPLE and FORCE comes from EATL. Figure 5c, d also show that, in this region, FORCE has a stronger TC activity and cyclogenesis than COUPLE. Furthermore, Fig. 6b shows that the difference between FORCE and COUPLE is significant over 
(a) DENSITY

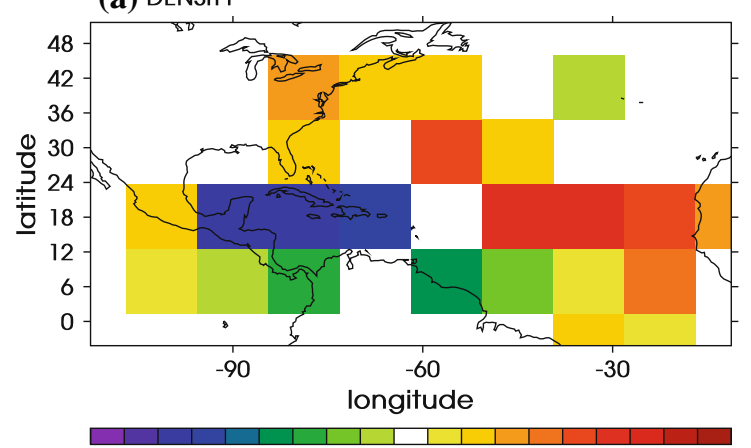

$-10050-40-30-20-15-12-9-6 \quad-3 \quad 3 \quad 6 \quad 9 \quad 121520304050100$ (b) 1- Pvalue x 100

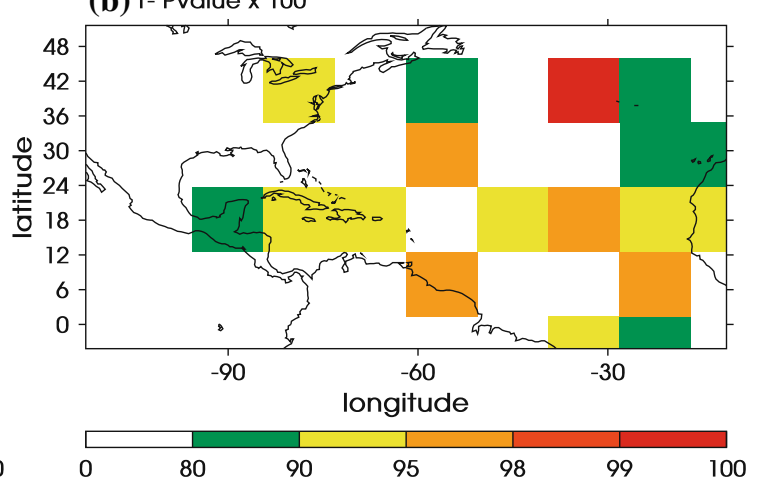

Fig. 6 Difference in TC track density per 20 years over a $10^{\circ}$ by $10^{\circ}$ grid over the North Atlantic basin between FORCE and COUPLE (a) and the level of significance of the difference (b) over 107 years of simulation

the MDR. Therefore, one may ask whether AEWs play a role in this difference. Previous studies (e.g. Avila and Pasch 1992; Landsea 1993) demonstrated that, in observations, AEWs accounted for about 50-60\% of all Atlantic tropical storms and minor hurricanes (categories 1 and 2), and nearly $85 \%$ of intense hurricanes (categories 4 and 5).

Figure 7 shows the 2-6 day filtered meridional wind variance at $850 \mathrm{hPa}$ for COUPLE (a) and FORCE (b) during the simulated 107 JAS seasons. Both simulations present a maximum over the west African ocean-continent transition. The maximum is located around $10^{\circ} \mathrm{N}-25^{\circ} \mathrm{N}$ and from $5^{\circ} \mathrm{E}$ to $30^{\circ} \mathrm{W}$. The amplitude of the activity is about $17 \mathrm{~m}^{2} \mathrm{~s}^{-2}$ for FORCE (Fig. 7a) and $15.5 \mathrm{~m}^{2} \mathrm{~s}^{-2}$ for COUPLE (Fig. 7b). Figure $3 d$ and e have already presented the AEW activity for the ERA-40 and NCEP-2 reanalysis respectively, over the time period 1980-2000. Simulated AEW activity is overestimated by FORCE and COUPLE in comparison with the reanalysis. The spatial structure of variance of both the simulations and the reanalysis are similar. Figure $7 \mathrm{c}$ presents the difference between FORCE and COUPLE in terms of AEW activity. A significant difference (Fig. 7c) over continental Africa and the near ocean indicates that FORCE is more active, even though the difference does not exceed $10 \%$. Counting the waves passing over the West African continent $\left(6-18^{\circ} \mathrm{N} ; 0-10^{\circ} \mathrm{W}\right)$ shows nearly the same number of waves in COUPLE and FORCE. Therefore, the difference in AEW activity between COUPLE and FORCE comes from the intensity of the waves. These results agree with the conclusions of Daloz et al. (2012) concerning the strong relationship between the AEW and TC activities in the MDR from CMIP-3 model results. Moreover, although AEWs result mostly from continental processes, it seems that the ocean-atmosphere coupling has a moderating influence on their development over the continent. Also, over the ocean, AEWs in COUPLE cool the SSTs, giving an environment less favourable for the development of TCs over the eastern MDR. The last two points are clearly illustrated by Fig. 8 .

Figures $8 \mathrm{a}, \mathrm{b}$ present composites of SST for COUPLE over the eastern North Atlantic Ocean and the west of continental Africa for 1909 to 2015. The composites were formed as follows. Dates selected for the composite were chosen in such a way that 2-6 days filtered northward wind at $850 \mathrm{hPa}$ was maximum in the black boxes indicated on the figures, allowing the selection of strong waves for the composite. The dates selected are designated as "t0". The lag composites represent the difference between the times "t0 + 3 days" and "t0". In Fig. 8a, b waves are not selected at the same time in their life cycle. With a black box close to the west African coast, in Fig. 8a we select the waves leaving the continent whereas, in Fig. 8b, the waves propagating over west Africa are considered. Figure $8 \mathrm{a}$ clearly shows that the interaction of the waves with the Atlantic SSTs leads to a cooling near the African coast for the waves leaving the continent. The cooling reaches $0.7^{\circ} \mathrm{C}$. This is not negligible since it is an average of several waves leaving the continent where the maximum cooling position may vary from one wave to another. Figure $8 \mathrm{~b}$ shows that, for the waves propagating over west Africa the cooling is located over the Gulf of Guinea. The Gulf of Guinea is already known to be a key region for the African climate. The feedback of this induced SST anomaly on the wave may partly explain the difference in AEW activity between FORCE and COUPLE in Fig. 7c.

As already mentioned, Fig. 5d presents the difference between FORCE and COUPLE in the density of TC genesis per 50 years in $5^{\circ} \times 5^{\circ}$ grid cells over the North Atlantic basin for the 107 years of simulation. Figure 5d clearly shows that FORCE produces more TCs off the west African coast than COUPLE. This is consistent with the results obtained in Figs. 5c and 7c. In FORCE, higher AEW activity combined with the absence of SST cooling off the coast of Africa leads to more genesis in this region at the expense of the western Atlantic. This difference of pattern 
(a) COUPLE

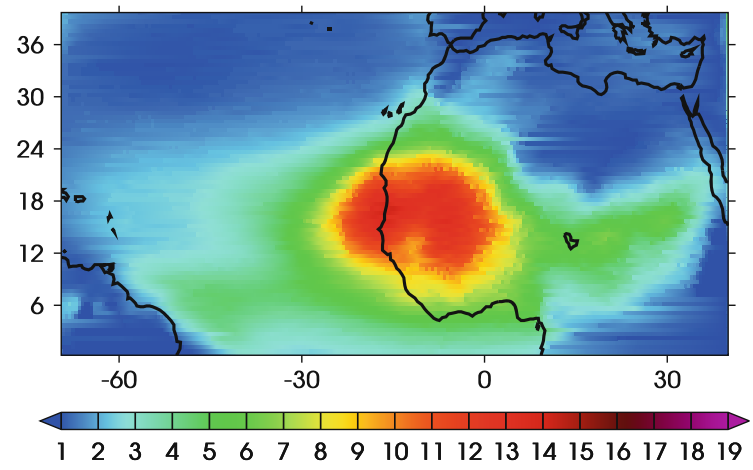

(c) FORCE - COUPLE

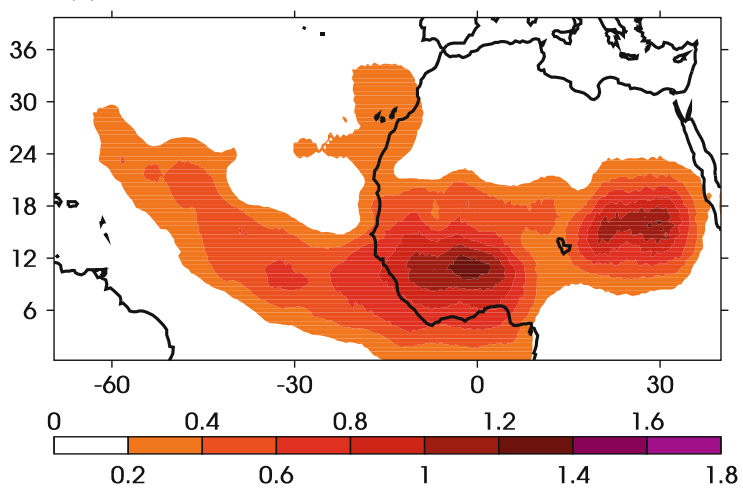

(b) FORCE

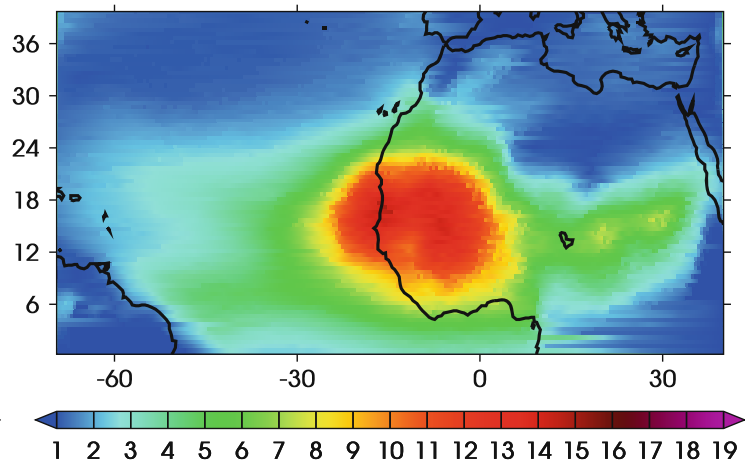

Fig. 7 Same as Fig. 3 but for FORCE and COUPLE over 107 years of simulation

(a) AEWs leaving the West African continent

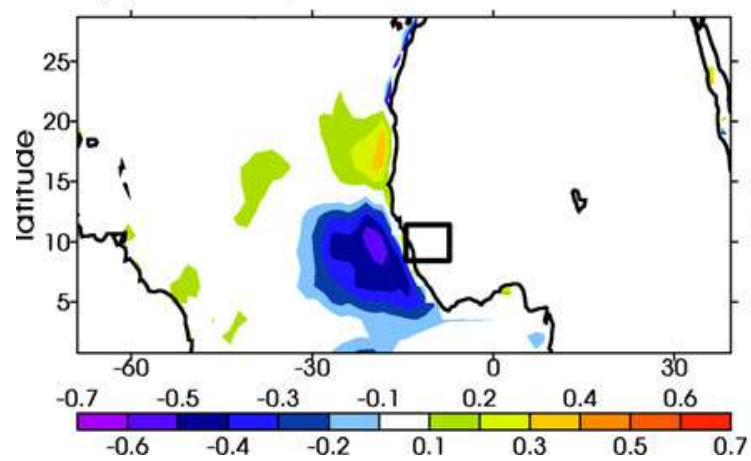

Fig. 8 Composites of SST $\left({ }^{\circ} \mathrm{C}\right)$ for COUPLE, difference between t0 + 5 days and t0 from 1909 to 2015 for the waves leaving continental west Africa (a) and the waves propagating over

in TC genesis between FORCE and COUPLE can also explain the difference in localization (east/west competition) in TC track density from Fig. 5c. As Caron et al. (2010) and Murakami and Wang (2010) have already suggested, the changes in TC activity mainly originate from changes in genesis locations. Counting the number of TCs moving through a line on longitude $50^{\circ} \mathrm{W}$ (not presented here) showed that there were $30 \%$ more TCs passing between $5^{\circ} \mathrm{N}$ and $15^{\circ} \mathrm{N}$ in COUPLE than in FORCE and (b) AEWs propagating over the West African continent

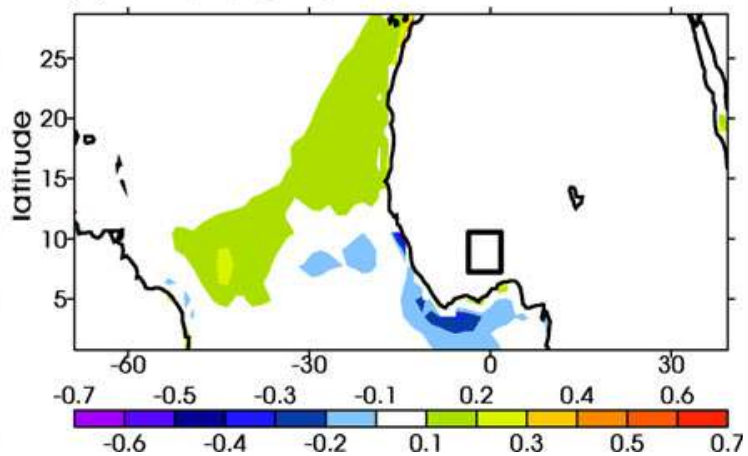

continental west Africa (b). The black box indicates where the waves have to reach a wind maximum. The wind is $2-6$ day filtered

conversely in the section $15^{\circ}-25^{\circ} \mathrm{N}$. In FORCE, TCs are more likely to be born off the west African coast and then recurve earlier, moving northward more frequently than in COUPLE. Whether cyclogenesis differences over the Gulf of Mexico and the Caribbean Sea are linked with MDR or due to local feedbacks is not easy to investigate, but it may be suggested that AEWs in COUPLE are expected to reach the western side of the Atlantic more often than in FORCE for the reasons just stated before. 


\section{Sensitivity of TC activity to the coupling frequency}

Figure 9 presents the TC track density per 20 years per $2^{\circ} \times 2^{\circ}$ grid cells for COUPLE24 (a, cf. Table 1) and COUPLE3 (b, cf. Table 1) and the difference between COUPLE24 and COUPLE3 (c) over the whole North Atlantic basin from 1850 to 1994 . The patterns of TC activity are very similar between COUPLE24 and COUPLE3. Both simulations find maxima over the Gulf of Mexico, the Caribbean Sea and the MDR. However, the amplitudes of the maxima of TC activity are quite different. COUPLE24 is generally more active over the North Atlantic basin than COUPLE3. The maxima of TC activity in COUPLE24 are more extended than for COUPLE3. Increasing the coupling frequency from $1 / 24$ to $1 / 3 \mathrm{~h}$ modifies the amplitude of TC activity but the spatial patterns of the distribution itself is not affected. To explain these differences, it can be argued that, at a $1 / 24 \mathrm{~h}$ frequency, a TC may have moved such that the cold SST feedback cannot interact with the TC itself. At $3 \mathrm{~h}$, the reduced SST driven by the TC will decrease latent heat flux feeding the system and thus decrease its intensity. Schade and Emanuel (1999) showed that, in an idealized model, the intensity reduction due to the negative feedback of the ocean on the TC could reduce the TC intensity by more than $50 \%$. Increasing the coupling frequency increases the interaction of the TCs with the ocean, certainly enhancing the feedback of the cold wake created by TCs. If, for example, " $\mathrm{t} 0$ " is considered as the beginning of a time step in COUPLE24 and also the time when a TC appears, then until "t0 $+24 \mathrm{~h}$ ", there is no exchange of information between the ocean and the atmosphere. So, it is only at "t0 $+24 \mathrm{~h}$ " that the ocean will receive the information from the TC. And it is only at " $0+48 \mathrm{~h}$ " that the effect of the TC on SST will retroact on the TC itself. This is certainly one of the reasons why the effect of TC on SST is underestimated in COUPLE24. Moreover, coupling every $24 \mathrm{~h}$ results in smoothed TC intensities "seen" by ocean, thus decreasing the cooling and feedback onto the atmopshere. Lower cooling will also have a fewer effect on subsequent TCs that may occur in the 2 or 3 weeks after the TC. Lin et al. (2003) using satellite data speculated that the cold wake induced by the typhoon Rusa (2002) may have had some negative impact on the typhoon Sinlaku which came a week later. In COUPLE24 this effect is certainly underestimated.

In order to evaluate the reliability of the coupled model, Fig. $9 \mathrm{~d}$ presents the TC track density per 20 years per $2^{\circ} \times 2^{\circ}$ grid cells over the North Atlantic basin from IBTrACS for the period 1950-2007 during which the data (a) COUPLE24

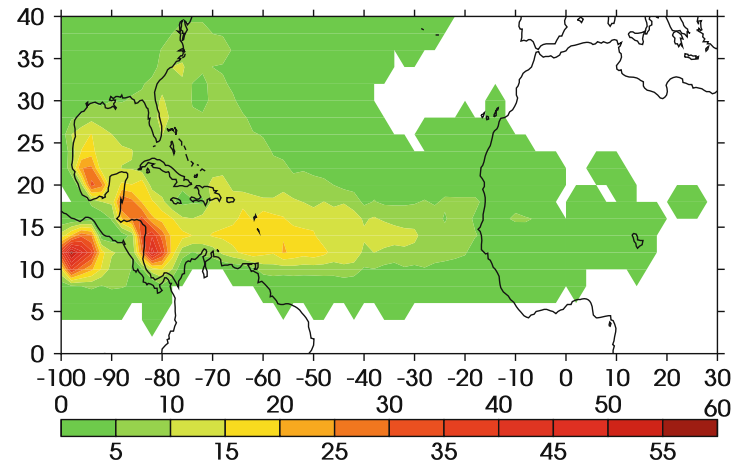

(c) COUPLE24 - COUPLE3

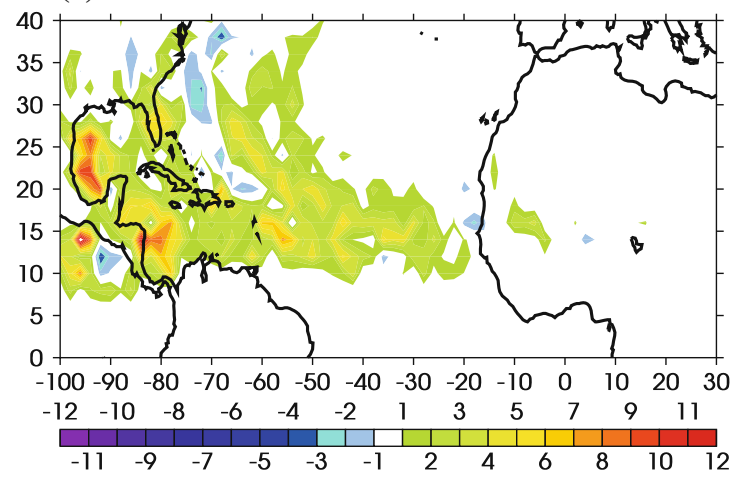

(b) COUPLE3

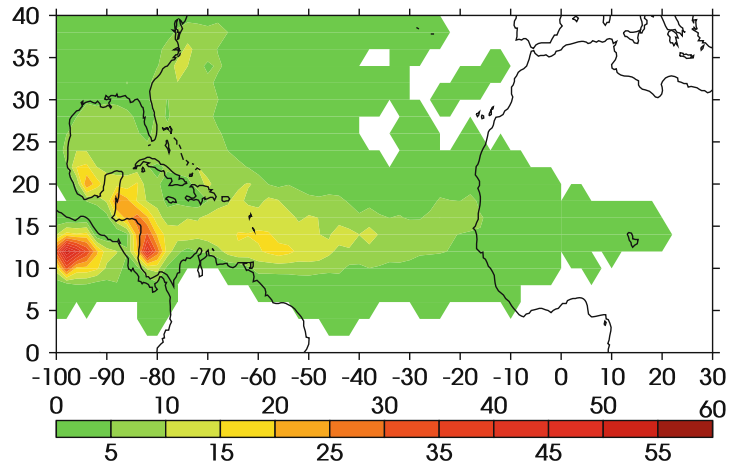

(d) IBTrACS

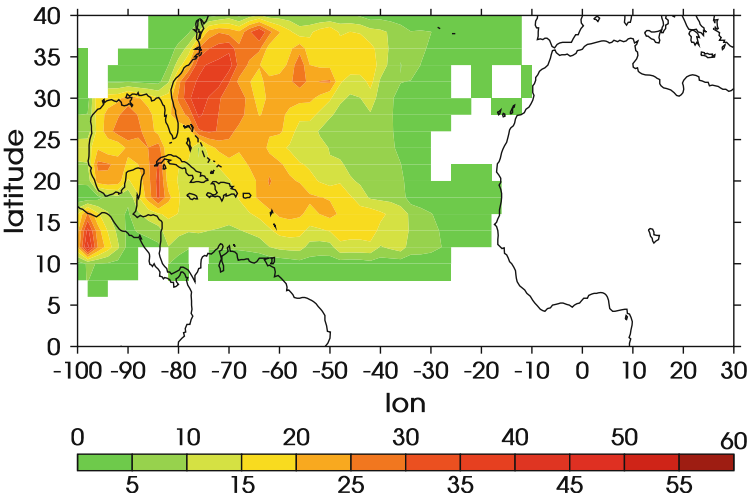

Fig. 9 Same as Fig. 2 but for COUPLE24 and COUPLE3 from 1850 to 1994 and IBTrACS from 1950 to 2007 
set accuracy is maximum. Compared to the observations, the relative distribution of simulated TCs for COUPLE24 and COUPLE 3 is fairly realistic in the Gulf of Mexico, the Caribbean Sea and the MDR. However, compared to the observations both simulations strongly underestimate the TC activity in a region over eastern Florida. This underestimate is clearly an effect coming from the simulated SSTs since they are cooler than the SSTs observed in this region (not presented here).

The technique introduced in Sect. 4 to test significance in track densities is again used here and results are shown in Fig. 10. The differences between COUPLE24 and COUPLE3 (Fig. 9c) are statistically significant, over a major part of the North Atlantic basin (Fig. 10b). Grid cells with a level of significance over $95 \%$ are present over a large part of the MDR, all the Gulf of Mexico and the Caribbean Sea.

Beyond the difference in TC track density (Fig. 9c), the change of coupling frequency can also induce modifications in the nature of the TC itself. To estimate this impact and understand the differences between COUPLE24 and COUPLE3, composites of TCs were constructed over the North Atlantic basin for 1850-1994. To make these composites, a land-sea mask was first applied to the precipitation and SST data in order to select only ocean points. Then, at each point, the precipitation and the SST were derived on $10^{\circ} \times 10^{\circ}$ boxes centred on the successive points of the tracks. Finally the boxes were averaged over all the points selected. Composites of wind and surface pressure had been realized but the differences between COUPLE24 and COUPLE3 were not conclusive.

Figure 11a presents the composite for the COUPLE24 simulation for precipitation. COUPLE24 reaches a maximum in precipitation of around $100 \mathrm{~mm}$ day $^{-1}$ on average. Figure $11 \mathrm{~b}$ presents the difference between COUPLE24 and COUPLE3 over the North Atlantic basin. COUPLE3 shows lower TC precipitation (Fig. 11b) than COUPLE24, the difference reaching between 6 and $7 \mathrm{~mm} \mathrm{day}^{-1}$.
A large sample test was applied. To apply this type of test, it is necessary to have independent data, which was not the case here as the successive occurrences of a track are linked to one another. In order to have the equivalent number of independent data, we can consider that each track is independent of the others. Therefore, if the total number of occurrences is divided by the mean duration of a track, the result can be considered as close to this equivalent number. In fact, this equivalent number is the number of TCs in the simulation. With around 10 TCs per year over a time period of 145 years, a simulation presents around 1500 independent elements per sample and the conditions of applicability of the large sample test are therefore satisfied. The black line in Fig. 11b indicates where the difference between COUPLE24 and COUPLE3 is significant at $95 \%$. Over the part of the composite where the difference is maximum (Fig. 11b), it is significant. The difference in precipitation between COUPLE24 and COUPLE3 represents around $8 \%$ of the total, which is not negligible.

Figure 11c presents a composite of SST for COUPLE24, and Fig. 11d the difference between COUPLE24 and COUPLE3 over the time period from 1850 to 1994 over the North Atlantic basin. Figure 11c shows that COUPLE24 reaches a maximum in SST, around $27.6{ }^{\circ} \mathrm{C}$, on the south west part of the TCs and decreasing northeastward. This reflects both the summer SW-NE SST gradient in tropical Atlantic and the cold wake appearing in the right hand side of the TCs. The latter have been largely documented (Chang and Anthes 1978; Price 1981; Samson et al. 2009). Considering that COUPLE24 and COUPLE3 show the same pattern of TC occurrences, differences should not be due to differences in TC locations and may be thus interpreted as intrinsic changes. Figure 11d shows that the TCs of COUPLE3 see cooler SSTs than those of COUPLE24. On eastern side of the TCs, COUPLE3 presents SSTs that are $0.15{ }^{\circ} \mathrm{C}$ cooler on average than in COUPLE24. Although this difference is small, it is consistent with decreased precipitation in the core of the TC. (a) DENSITY

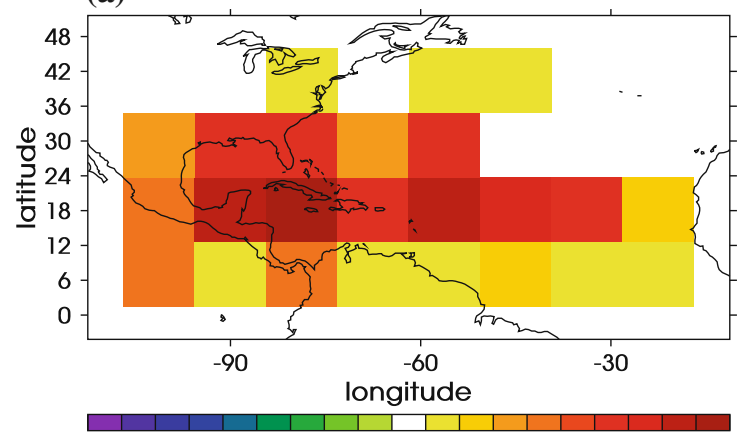

$-10050-40-30-20-15-12-9$-6 $-3 \quad 3 \quad 6 \quad 9 \quad 121520304050100$ (b) 1-Pvalue $\times 100$

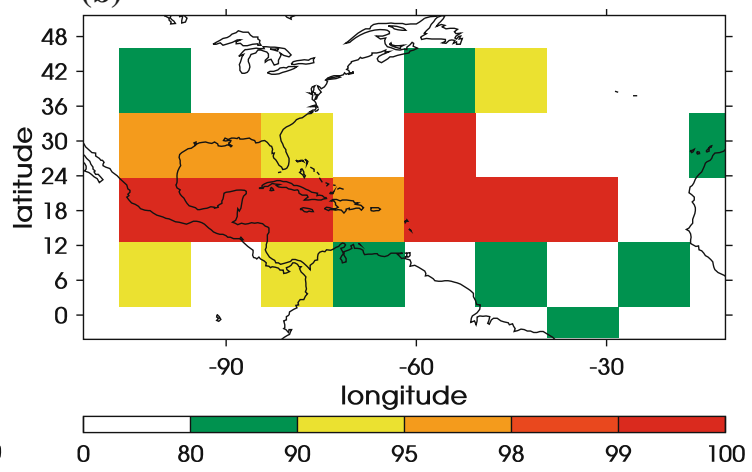

Fig. 10 Same as Fig. 6 but for COUPLE24 and COUPLE3 over the period 1850-1994 
(a) COUPLE24

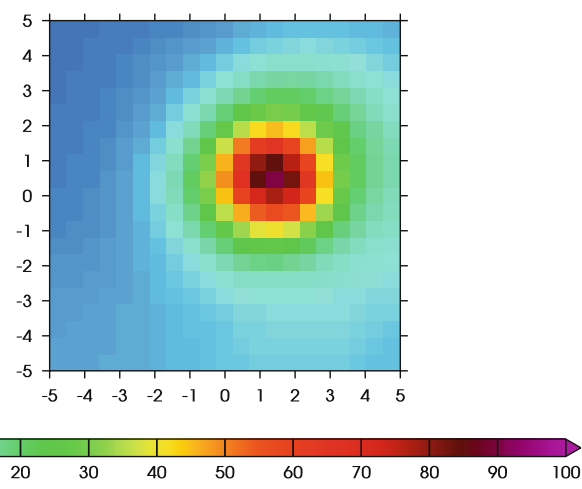

(c) COUPLE24

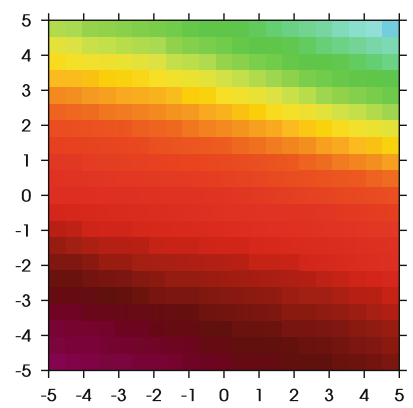

$\begin{array}{llllllllllllll}25.0 & 25.2 & 25.4 & 25.6 & 25.8 & 26.0 & 26.2 & 26.4 & 26.6 & 26.8 & 27.0 & 27.2 & 27.4 & 27.6\end{array}$ (b) COUPLE24 - COUPLE3

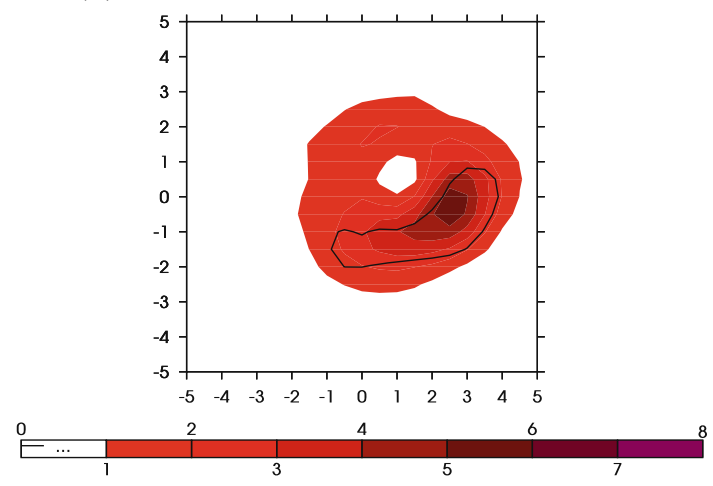

(d) COUPLE24 - COUPLE3

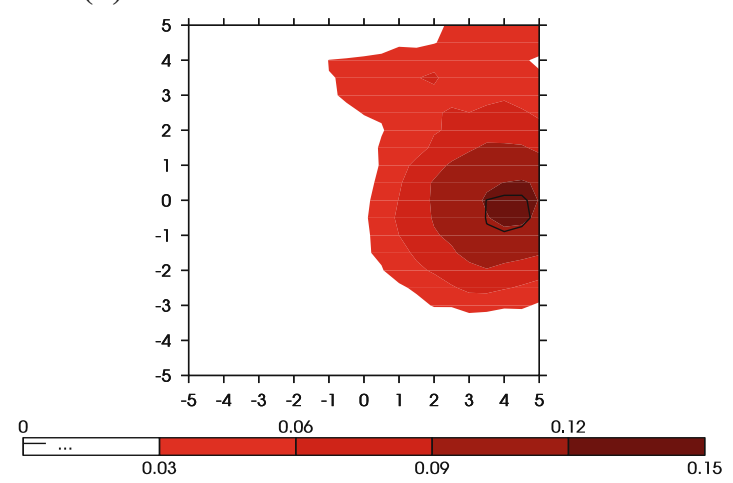

Fig. 11 Composites of precipitation $\left(\mathrm{mm} \mathrm{day}^{-1}\right)$ and SST $\left({ }^{\circ} \mathrm{C}\right)$ over the North Atlantic basin for COUPLE24 (a, c) and the difference (COUPLE24-COUPLE3) (b, d) for 1850-1994. $x$-axis and $y$-axis are in degrees

Moreover, the difference is significant, which suggests that the cooling effect is systematic. In COUPLE24, with an interaction between the TC and the ocean every $24 \mathrm{~h}$, the TC does not see the retroaction of the SST anomalies that it has produced on its way. Therefore, the TC is more intense, explaining the stronger response of COUPLE24 in precipitation (Fig. 11b) and TC activity (Fig. 9c).

From Figs. 9 and 11, we can see that the sensitivity of TC activity to the frequency of coupling is noticeable. However, even though COUPLE24 misses a part of the TC-ocean feedback, the differences between COUPLE24 and COUPLE3 are only visible in the amplitude of the density and the composites. The differences are not visible on spatial structures. We can thus expect that sensitivity of TC activity to climate should not be changed by less frequent coupling. Because of computational costs, a coupling frequency of $1 / 24 \mathrm{~h}$ has been adopted in this study (cf. Sect. 4). However, for forthcoming studies, the use of a coupling frequency of $1 / 3 \mathrm{~h}$ is recommended so as to better simulate the processes inside TCs.

\section{Conclusions}

In most past studies, the atmosphere-ocean interaction was neglected by using an active atmosphere and a passive ocean, such that any feedback effects were excluded a priori. This choice is explained partly by the computational cost of the simulations. In recent decades, most of the efforts made in GCMs have been on the horizontal resolution, as a minimum resolution is necessary to study TCs. In this paper, we suggest a new and different perspective for the study of TCs, combining high resolution with ocean-atmosphere coupling. Compared to the previous configurations of ARPEGE, the coupled and forced simulations are much more active over the eastern Atlantic. This is a step towards more realistic TC climatology since previous configurations clearly underestimated the number of TCs in this region.

This paper first examines the impact of the configuration of the stretched grid on TC activity over the North Atlantic basin. This part used simulations with two different positions of the pole of stretching, one with the pole in the center of the North Atlantic basin and one with the pole over the West African coast. This study showed that for the simulation with the eastern pole, the higher TC activity over the eastern Atlantic basin is due to the higher spatial resolution and not to the AEW activity. Given the strong link known between AEW and TC activities over the MDR, this is a surprising result. We also noticed that specific parameters of the convective scheme could heavily 
influence TC development. Indeed, TCs are very sensitive to the formulation of the convergence of humidity, through the convective precipitation. Convergence of humidity in the simulations is sensitive to local resolution and may explain changes in precipitation when moving the pole of the grid.

Through the investigation of the impact of atmosphereocean coupling on TC activity over the North Atlantic basin, this study has shown that the coupling impacts the spatial distribution of TC activity. The coupled simulation is more active in the Caribbean Sea, the Gulf of Mexico and western MDR, while the forced simulation is more active over a region east of the Florida coast and over the eastern MDR.

The key role of the eastern Atlantic stems from two distinct features. The first is the amplitude of the AEW activity. The forced simulation presents a higher activity than the coupled one, which is more favourable to the genesis of TCs. Secondly, due to the interactions between local SST and AEWs, in the coupled simulations, AEWs tend to cool the SSTs close to the west African coast, inhibiting the near African genesis. The result is that TCs develop further west in the coupled simulation than in the forced simulation. This leads to weaker activity near Carolina and South Carolina, confirming the results from Murakami and Wang (2010) and Caron et al. (2010). TCs that formed close to the west African coast usually recurved earlier and moved northward to the eastern Florida region. On the other hand, TCs that formed further recurved later, moving to the Caribbean Sea and the Gulf of Mexico.

We saw that the relationship between the AEW activity and TCs was not always direct. In the first experiment of this study, concerning the position of the pole of stretching, the AEW activity decreases when the pole is located in the eastern part of the basin while TC activity is strengthened there. Thus, this cannot be explained by a dynamic cause. On the contrary, for the second experiment, presenting the comparison of coupled and forced simulations, for a given configuration of ARPEGE grid, the activity of the AEWs corresponds to that of TCs (Figs. 5, 7). So, it is a combination of dynamic and thermal causes that explains TC density. In the first part of the result, the precipitation (thermal condition) drives the increase of TC activity, while in the second part, it is the intensity of the AEWs (dynamic condition).

The impact of the coupling frequency on TC activity over the North Atlantic basin has been tested with simulations of $1 / 24$ and $1 / 3 \mathrm{~h}$ frequencies. It was found that, with a $1 / 24 \mathrm{~h}$ coupling frequency, the cooling effect due to a TC to the TC itself is weak since the system had already moved on when the effect of the cooler SST was brought back to the atmosphere. Nevertheless, the cooling effect due to one TC on subsequent TCs must be non-negligible.
Indeed, Price et al. (2008) showed that the cooling effect of a TC can last until 20 days. Thus, as the simulations present around 15 systems per year, it gives a chance for one TC to act on a subsequent TC. Nevertheless, due to the 24-h averaging effect of the moving TC, the intensity of the TC that inputs the ocean is probably underestimated and the feedback of the ocean on the system itself is partly missed. Increasing the coupling frequency to $1 / 3 \mathrm{~h}$ decreases the number of occurrences of TCs. This confirms the importance of the coupling frequency in the oceanic feedback on TCs. When coupling every $3 \mathrm{~h}$, the interaction between atmosphere and ocean is better taken into account since the oceanic cooling is located right under the TC while in the $1 / 24 \mathrm{~h}$ coupling frequency experiment, the TC has already moved on when ocean "feels" the cooling. As a consequence, in the $1 / 3 \mathrm{~h}$ coupling experiment, the feedback of the cooled ocean mixed layer on the TC itself is stronger and the result is a global weakening of the simulated TCs. Nevertheless, it is noteworthy that the spatial distribution of TCs is not modified. This latest point gives confidence in the ability of the $1 / 24 \mathrm{~h}$ coupling frequency experiments to represent the climatology of TCs over the Atlantic and further on to capture its sensitivity to anthropogenic global warming. However with further increase in spatial resolution and improved representation of mechanism like convection, more frequent coupling is likely to become necessary in the future.

This study confirms that the eastern Atlantic is a crucial region for TCs and shows that it is sensitive to atmosphereocean coupling. Moreover, coupling effects between TC and the underlying ocean are not expected to be independent of the global climate. In a different climate equilibrium, TCs may behave quite differently and therefore induce a different forcing to the ocean, changing also the feedback from the latter onto TCs. Thus, whether oceanatmosphere coupling also impacts the response of TC activity to global warming is still to investigate and will be the subject of a forthcoming paper.

Acknowledgments Thanks to the two reviewers for insightful comments on this work. The authors would like to thank Aurelien Ribes for the statistical advices. The authors are also grateful for the availability of IBTrACS, ERA-40 and NCEP-2 reanalysis.

\section{References}

Arnault J, Roux F (2011) Characteristics of African easterly waves associated with tropical cyclogenesis in the Cape Verde Islands region in July-August-September of 2004-2008. J Atmos Res. doi:10.1016/J/atmosres.2010.12.028

Avila LA, Pasch RJ (1992) Atlantic tropical systems of 1991. Mon Weather Rev 120:2688-2696

Ayrault F, Joly A (2000) Une nouvelle topologie des dépressions météorologiques: classification des phases de maturation. CR Acad Sci Sci Terre planètes 30:167-172 
Bender MA, Ginis I (2000) Real-case simulations of hurricane-ocean interaction using a high-resolution coupled model: effects on hurricane intensity. Mon Weather Rev 128:917-946

Bender MA, Ginis I, Kurihara Y (1993) Numerical simulations of tropical cyclone-ocean interaction with a high resolution coupled model. J Geophys Res 98:23245-23263

Bengtsson L, Bottger H, Kanamitsu M (1982) Simulation of hurricane-type vortices in a general circulation model. Tellus 34:440-457

Bengtsson L, Bozet M, Esh M (1995) Hurricane-type vortices in a general circulation model. Tellus 47A:175-196

Bernie D, Woolnough S, Slingo J (2005) Modeling diurnal and intraseasonal variability of the ocean mixed layer. J Clim 18:1190-1202

Bougeault P (1985) A simple parameterization of the large-scale effects of cumulus convection. Mon Weather Rev 113:21082121

Burpee RW (1972) The origin and structure of Easterly Waves in the lower troposphere of Nort Africa. J Atmos Sci 29:77-90

Camargo S, Zebiak S (2002) Improving the detection and tracking of tropical cylones in atmospheric general circulation models. Weather Forecast 17:1152-1162

Carlson T (1969) Synoptic histories of three African disturbances that developed into Atlantic hurricanes. Mon Weather Rev 97:256-276

Caron LP, Jones C, Winger K (2010) Impact of resolution and downscaling technique in simulating recent tropical cyclone activity. Clim Dyn. doi:10.1007/s00382-010-0846-7

Chang SW, Anthes RA (1978) Numerical simulations of the ocean's nonlinear, baroclinic response to translating hurricanes. J Phys Oceanogr 8:468-480

Chauvin F, Royer JF, Déqué M (2006) Response of hurricane-type vortices to global warming as simulated by ARPEGE-Climat at high resolution. Clim Dyn 27:377-399

Courtier P, Geleyn JF (1988) A global numerical weather prediction mode with variable resolution: application to a shallow water equation. QJR Meteorol Soc 114:1321-1346

Daloz AS, Chauvin F, Walsh K, Lavender S, Abbs D, Roux F (2012) The ability of GCMs to simulate tropical cyclones and their precursors over the North Atlantic main development region. Clim Dyn. doi:10.1007/s00382-012-1290-7

Emanuel KA (1988) The maximum intensity of hurricanes. J Atmos Sci 45:1143-1155

Emanuel KA (2003) A similarity hypothesis of air-sea exchange at extreme wind speeds. J Atmos Sci 60:1420-1428

Emanuel KA (2005) Increasing destructiveness of tropical cyclones over the past 30 years. Nature 436:686-688

Fox-Rabinovitz M, Cote J, Dugas B, Deque M, McGregor JL (2006) Variable resolution general circulation models: stretched-grid model intercomparison project (SGMIP). J Geophys Res 111:D16104. doi:10.1029/2005JD006520

Goldenberg SB, Shapiro LJ (1996) Physical mechanisms for the association of the El Nino and the West African rainfall with the Atlantic major hurricane variability. J Clim 9:1169-1187

Holland GJ (1997) The maximum potential intensity of tropical cyclones. J Atmos Sci 54:2519-2541

Hopsch S, Thorncroft CD, Hodges K, Aiyyer A (2007) West African storm tracks and their relationship to Atlantic tropical cyclones. J Clim 20:2468-2483

Hsieh J-S, Cook KH (2005) Generation of African Easterly Wave disturbances: relationship to the African Easterly Jet. Mon Weather Rev 133:1311-1327

Kanamitsu M, Ebisuzaki W, Woolen J, Hnilo J, Fiorino L et al (2002) NCEP-DOE AMIP-II reanalysis (R-2). Bull Am Meteorol Soc $83: 1631-1643$
Klingaman N, Woolnough S, Weller H, Slingo J (2011) The impact of finer-resolution air-sea coupling on the intraseasonal oscillation of the Indian monsoon. J Clim 24(10):2451-2468

Knapp KR, Kruk MC, Levinson DH, Diamond HJ, Neumann CJ (2010) The International Best Track Archive for Climate Stewardship (IBTrACS): unifying tropical cyclone best track data. Bull Am Meteorol Soc 91:363-376

Landsea CW (1993) A climatology of intense (or major) Atlantic hurricanes. Mon Weather Rev 121:1703-1713

Landsea CW, Gray W (1992) The strong association between western Sahelian monsoon rainfall and intense Atlantic hurricanes. J Clim 5:435-453

Lebeaupin-Brossier C, Ducrocq V, Giordani H (2009) Effects of airsea coupling time frequency on the ocean response during Mediterranean intense events. Ocean Dyn 54(4):539-549

Lin I-L, Liu WT, Wu C-C, Chiang JCH, Sui C-H (2003) Satellite observations of modulation of surface winds by typhoon-induced upper ocean cooling. Geophys Res Lett 30(3):1131. doi: 10.1029/2002GL015674

Madec G (2008) NEMO ocean engine. Note du pôle modélisation, Institut Pierre-Simon Laplace (IPSL), France, No 27 ISSN 1288-1619

Malkus JS, Riehl H (1960) On the dynamics and energy transformation in steady-state hurricanes. Tellus 12:1-20

Mlawer EJ, Taubman SJ, Brown PD, Iacono MJ, Clough SA (1997) Radiative transfer for inhomogeneous atmosphere: RRTM, a validated correlated-k model for longwave. J Geophys Res 102:16663-16682

Murakami H, Wang B (2010) Future change of North Atlantic tropical cyclone tracks: projection by a $20-\mathrm{km}-\mathrm{mesh}$ global atmospheric model. J Clim 23:2699-2721

Oki T, Sud YC (1998) Design of total runoff integrating pathways (TRIP). A global river channel network. Earth Interact 2:1-36

Price JF (1981) Upper ocean response to a hurricane. J Phys Oceanogr 11:153-175

Price JF, Morzel J, Niiler PP (2008) Warming of SST in the cold wake of a moving hurricane. J Geophys Res 113. doi:10.1029/ 2007JC004393

Rayner NA, Parker DE, Horton EB, Folland CK, Alexander LV, Rowell DP, Kent EC, Kaplan A (2003) Global analyses of SST, sea ice and night marine air temperature since the late nineteenth century. J Geophys Res 108:4407. doi:10.1029/2002JD002670

Reed RJ, Norquist DC, Recker EE (1977) The structure and properties of African wave disturbances as observed during phase III of GATE. Mon Weather Rev 105:317-333

Renaudie C (2009) Etude et validation des couches limites atmospheriques et oceanique a 1 echelle locale. $\mathrm{PhD}$, University of Toulouse, France

Ricard JL, Royer JF (1993) A statistical cloud scheme for use in an AGCM. Ann Geophys 11:1095-1115

Royer JF, Chauvin F, Timbal B, Araspin P, Grimal D (1998) A GCM study of the impact of greenhouse gas increase on the frequency of occurrence of tropical cyclones. Clim Change 38:307-343

Ruti PM, Dell Aquilla A (2010) The twentieth century African easterly waves in reanalysis systemes and IPCC simulations, from intra-seasonal to inter-annual variability. Clim Dyn 35:1099-1117

Salas-Mélia D (2002) A global coupled sea ice-ocean model. Ocean Model 4:137-172

Samson G, Giordani H, Caniaux G (2009) Numerical investigation of oceanic resonant regime induced by hurricane winds. Ocean Dyn 59:565-586

Schade L, Emanuel K (1999) The ocean's effect on the intensity of tropical cyclones: results from a simple coupled atmosphereocean model. J Atmos Sci 56:642-651 
Schultz M (2007) Constraining model estimates of the aerosol radiative forcing. Habilitation thesis, Université Pierre et Marie Curie

Szopa S, Cozic A, Schulz M, Balkanski Y, Hanglustaine (2012) Changes in tropospheric aerosol and reactive gas burdens and concentrations under IPCC-AR5 emission scenarios for 1850-2100. Clim Dyn, Special issue on the IPSL and CNRM global climate and Earth System Models

Uppala S, Kallberg P, Simmons U, Jand A, Betchold V, Fiorino M et al (2005) The ERA-40 reanalysis. QJR Meteorol Soc 131:2961-3012
Valcke S (2006) OASIS3 user guide (prism 2-5). Technical report TR/CMCG/06/73, CERFACS, Toulouse, France, p 60

Voldoire A, Cassou C, Salas-Mélia D, Decharme B, Sanchez-Gomez E, Sénési S, Valcke S, Beau I, Alias A, Chevallier M, Déqué M, Douville H, Maisonnave E, Planton S, Saint-Martin D, Tyteca S, Alkama R, Belamari S, Braun A, Chauvin F, Szopa S (2011) The CNRM-CM5.1 global climate model description and basic evolution. Clim Dyn. doi:10.1007/s00382-011-1259-y 